\title{
The Negative Impact of the Hominin's DPP4 Gene Inherited from Neanderthals to Pandemic of COVID-19
}

\section{Niknamian $S^{*}$}

Department of Medicine, Liberty University, USA

*Corresponding author: Sorush Niknamian, Department of Medicine, Liberty University, USA, Email: So.niknamian@gmail.com

\section{Research Article}

Volume 4 Issue 1

Received Date: January 15, 2021

Published Date: March 11, 2021

DOI: $10.23880 /$ oajmms-16000135

\section{Abstract}

Background: According to preliminary sequences from 2010, $99.7 \%$ of the nucleotide sequences of the modern human and Neanderthal genomes are identical, compared to humans sharing around $98.8 \%$ of sequences with the chimpanzee. In contrast, the difference between chimpanzees and modern humans is approximately 1,462 mtDNA base pairs.

Materials and Methods: Neanderthal-inherited genetic material is found in all non-African populations and was initially reported to comprise 1 to 4 percent of the genome. This fraction was later refined to 1.5 to 2.1 percent. We had gone through many researches of Neanderthals affected gene flow in humans.

Results: It is estimated that 20 percent of Neanderthal DNA currently survives in modern humans. Modern human genes involved in making keratin, a protein constituent of skin, hair, and nails, have especially high levels of introgression. For example, approximately $66 \%$ of East Asians contain a POUF23L variant introgressed from Neanderthals, while $70 \%$ of Europeans possess an introgressed allele of BNC2. Our finding shines a light on an enzyme called dipeptidyl peptidase-4 (DPP4). Scientists already know the protein allows another coronavirus, which causes Middle Eastern respiratory syndrome (MERS), to bind to and enter human cells. The new analysis, of DPP4 gene variants among COVID-19 patients, suggests the enzyme also provides SARS-CoV-2 with a second door into our cells, along with its usual infection route via the angiotensinconverting enzyme 2 (ACE2) receptor on cell surfaces. Conclusion: Most Europeans, Asians, and Native Americans harbor a handful of genes from Neanderthals, up $1.8 \%$ to $2.6 \%$ of their DNA. Studies of ancient DNA in Neanderthal fossils have shown the hominin's DPP4 gene subtly differs from the typical human one.

Conclusion: The hominin's DPP4 gene inherited from Neanderthals plays a major role in Immune System Disorders and Lower Immune response in many diseases. This gene plays a major role in affecting humans with COVID-19 and spreading it through the world. All humans contain this gene from 1 to 4 percent. East Asians, Europeans, Middle and South Americans conveys more, hence; native Africans contain less amounts of hominin's DPP4 gene. Therefore; East Asians, Europeans, Middle and South Americans are prone to severe COVID-19.

Keywords: Neanderthals; Hominin's DPP4 Gene; DNA Viruses; RNA Viruses; COVID-19

Abbreviations: DPP4: Dipeptidyl Peptidase-4; MERS: Middle Eastern Respiratory Syndrome; ACE2: AngiotensinConverting Enzyme 2; AMH: Anatomically Modern Humans.

\section{Introduction}

\section{Neanderthal Ancient DNA}

Genetic studies on Neanderthal ancient DNA became possible in the late 1990s [1,2]. The Neanderthal genome project, established in 2006, presented the first fully sequenced Neanderthal genome in 2013. Since 2005, evidence for the substantial admixture of Neanderthals DNA in modern populations has accumulated [3-5]. The divergence time between the Neanderthal and modern human lineages is estimated at between 750,000 and 400,000 years ago. The more recent time depth has been suggested by Endicott $P$, et al. [6] and Rieux A, et al. [7]. A significantly deeper time of 


\section{Open Access Journal of Mycology \& Mycological Sciences}

separation, combined with repeated early admixture events, was calculated by Rogers AR, et al. [8]. On July 3, 2020, a team reported finding that a major genetic risk factor of the Covid-19 virus was inherited from archaic Neanderthals 60,000 years ago $[9,10]$.

\section{COVID-19}

SARS-CoV-19 which is better called COVID-21, are a group of viruses that cause diseases in mammals and birds. In humans, the beginning of Coronaviruses in 1919 cause's respiratory tract infections those are typically mild, such as some cases of the common cold. Rarer forms can be lethal, such as SARS, MERS, and COVID-19. Symptoms vary in other species: in chickens, they cause an upper respiratory tract disease, while in cows and pigs they cause diarrhea. Coronaviruses constitute the subfamily Orthocoronavirinae, The genome size, coronaviruses ranges from approximately 27 to 34 kilobases, the largest among known RNA viruses. In recent months, COVID-19 has become more severe which targets Respiratory Organ, Liver, Kidneys, Hearts and etc. The polarity of this virus is positive-sense $((+)$ ssRNA). Positive sense viral RNA is similar to mRNA and thus can be immediately translated by the host cell. Recombination in RNA viruses appears to be an adaptation for coping with genome damage. Recombination can occur infrequently between animal viruses of the same species but of divergent lineages. The resulting recombinant viruses may sometimes cause an outbreak of infection in humans. RNA viruses have very high mutation rates this is one reason why it is difficult to make effective vaccines to prevent diseases caused by RNA viruses. The resulting recombinant viruses cause an outbreak of infection in humans.

\section{Materials And Methods}

The question of possible interbreeding between Neanderthals and anatomically modern humans (AMH) had been looked into since the early archaeogenetic studies of the 1990s. In 2006, no evidence for interbreeding had yet been found [11]. In 2009, analysis of about one-third of the full genome of the Altai individual was still reported as showing no sign of admixture. The variant of microcephalin common outside Africa, which was suggested to be of Neanderthal origin and responsible for rapid brain growth in humans, was not found in Neanderthals. Nor was a very old MAPT variant which is found primarily in Europeans [12]. Positive evidence for admixture was first published in May 2010 [13]. Neanderthal-inherited genetic material is found in all nonAfrican populations and was initially reported to comprise 1 to 4 percent of the genome [14]. This fraction was later refined to 1.5 to 2.1 percent [15].

It is estimated that 20 percent of Neanderthal DNA currently survives in modern humans [16]. Modern human genes involved in making keratin, a protein constituent of skin, hair, and nails, have especially high levels of introgression. For example, approximately $66 \%$ of East Asians contain a POUF23L variant introgressed from Neanderthals, while $70 \%$ of Europeans possess an introgressed allele of BNC2.

Neanderthal variants affect the risk of developing several diseases, including lupus, biliary cirrhosis, Crohn's disease, type 2diabetes, and severe COVID-19 [17-19]. The allele of MC1R which was originally linked to red hair in Neanderthals is not found in Europeans, but is present in Taiwanese Aborigines at a frequency of $70 \%$ and moderately high frequencies in other East Asian populations; hence, there is no evidence that Neanderthals had red hair [20]. While interbreeding is viewed as the most parsimonious interpretation of these genetic findings, the 2010 study still could not conclusively rule out an alternative scenario, in which the source population of non-African modern humans was already more closely related to Neanderthals than other Africans were, because of ancient genetic divisions within Africa $[21,22]$.

Research since 2010 has refined the picture of interbreeding between Neanderthals, Denisovans, and anatomically modern humans. Interbreeding appears to have occurred asymmetrically among the ancestors of modernday humans, and that this is a possible rationale for differing frequencies of Neanderthal-specific DNA in the genomes of modern humans. Vernot B, et al. concluded that the relatively greater quantity of Neanderthal-specific DNA in the genomes of individuals of East Asian descent than those of European descent cannot be explained by differences in selection [23]. They further suggest that "two additional demographic models, involving either a second pulse of Neanderthal gene flow into the ancestors of East Asians or a dilution of Neanderthal lineages in Europeans by admixture with an unknown ancestral population" are parsimonious with their data [23]. Similar conclusions were reached by Kim BY, et al. [24]. "It has been hypothesized that the greater proportion of Neanderthal ancestry in East Asians than in Europeans is since purifying selection is less effective at removing weakly deleterious Neanderthal alleles from East Asian populations. Using simulations of a broad range of models of selection and demography, we have shown that this hypothesis cannot account for the higher proportion of Neanderthal ancestry in East Asians than in Europeans. Instead, more complex demographic scenarios, most likely involving multiple pulses of Neanderthal admixture, are required to explain the data".

Ekaterina EK, et al. [25], a German-Russian-Chinese collaboration, compiled a consensus Neanderthal genome based on the genome of the Altai individual and of three Vindjia individuals. This was compared to a consensus 
chimpanzee genome as the out-group and to the genome of eleven modern populations (three African, three East Asian, and three European). Beyond confirming the significantly higher similarity to the Neanderthal genome in nonAfricans than in Africans, the study also found a difference in the distribution of Neanderthal-derived sites between Europeans and East Asians, suggesting recent evolutionary pressures. Asian populations showed clustering in functional groups related to immune and hematopoietic pathways; while Europeans showed clustering in functional groups related to the lipid catabolic process. Evidence for $\mathrm{AMH}$ admixture to Neanderthals at roughly 100,000 years ago was presented by Martin K, et al. [26].

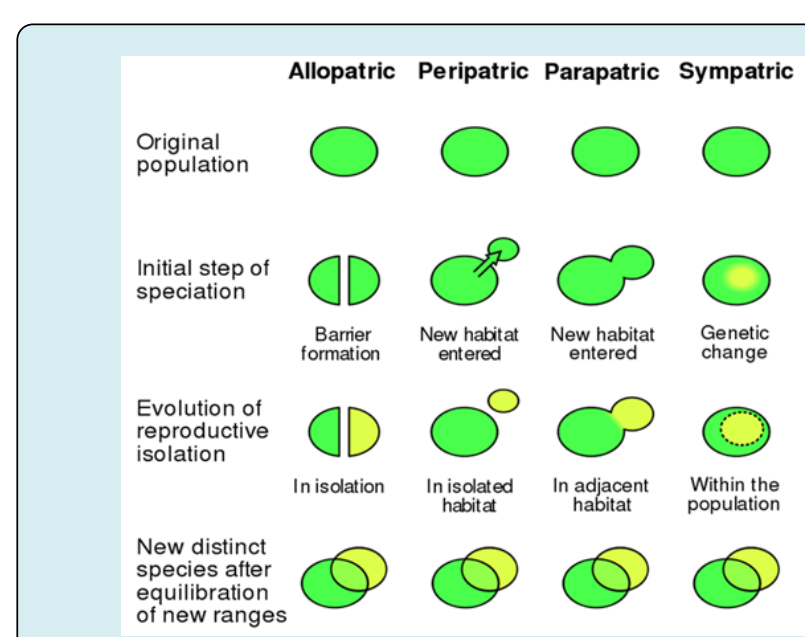

Figure 1: How Neanderthals affected gene flow in humans.

There have been at least three episodes of interbreeding. The first would have occurred soon after some modern humans left Africa. The second would have occurred after the ancestral Melanesians had branched off these people seem to have thereafter bred with Denisovans. The third would have involved Neanderthals and the ancestors of East Asians only [27-29].

A 2016 study presented evidence that Neanderthal males might not have had viable male offspring with AMH females. This could explain why no modern man to date has been found with a Neanderthal Y chromosome [30]. A 2018 study concluded that interbreeding between Neanderthals and modern humans led initially to the exposure of each species to unfamiliar viruses. Later on, the exchange of genes granted resistance to those viruses, too [31].

On July 3, 2020, scientists reported finding that a major genetic risk factor of the Covid-19 virus was inherited from archaic Neanderthals 60,000 years ago [7,8,32]. It is estimated that $16 \%$ of Europeans and $50 \%$ of South Asians have the particular sequence on chromosome III, with $63 \%$ of Bangladeshis having these gene sequences. Africans, Middle Easterners, and East Asians reported the presence of the chromosome in very negligible amounts [33-35].

If someone becomes infected with the coronavirus SARSCoV-2, he/she might wish there was a fast way to check his/ her Neanderthal ancestry. A small but significant number of people have an ancient gene variant from the extinct hominin that may double, or even quadruple, their risk of serious complications from COVID-19. The finding shines a light on an enzyme called dipeptidyl peptidase-4 (DPP4). Scientists already know the protein allows another coronavirus, which causes Middle Eastern respiratory syndrome (MERS), to bind to and enter human cells. The new analysis, of DPP4 gene variants among COVID-19 patients, suggests the enzyme also provides SARS-CoV-2 with a second door into our cells, along with its usual infection route via the angiotensin-converting enzyme 2(ACE2) receptor on cell surfaces [36-39].

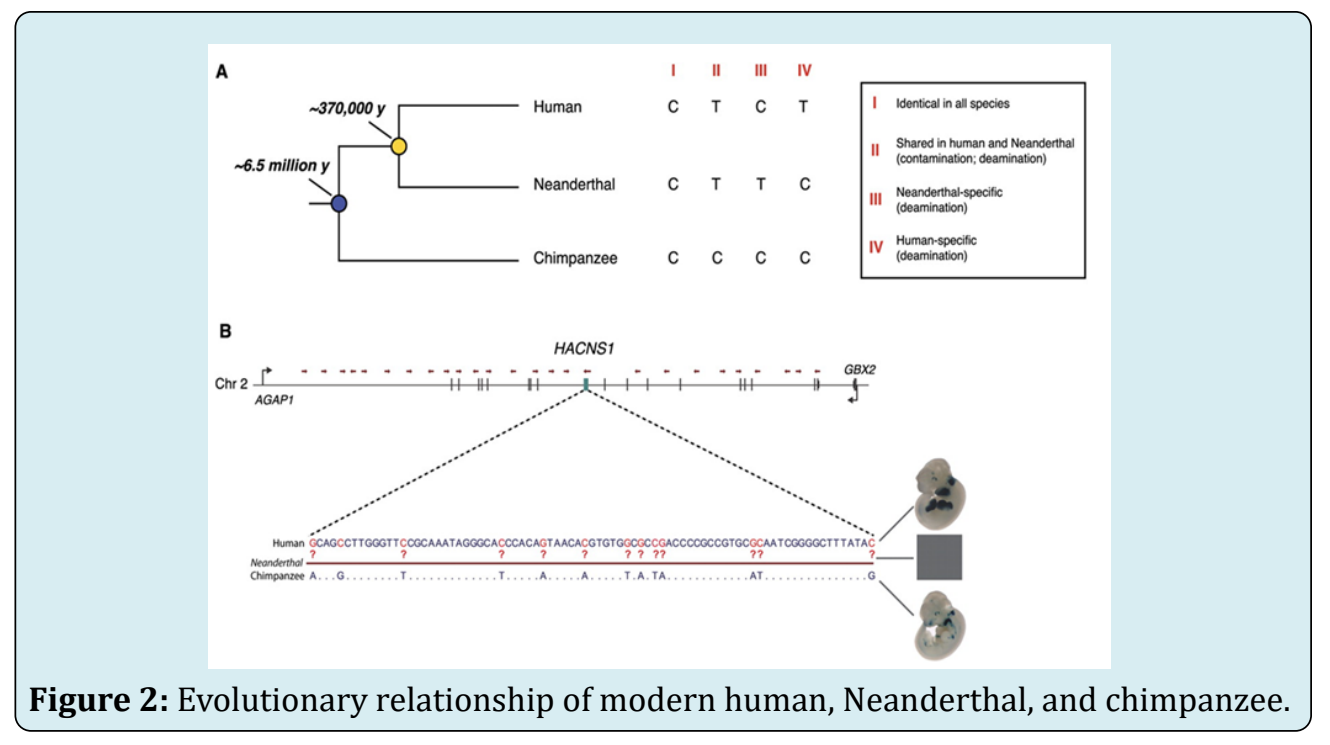




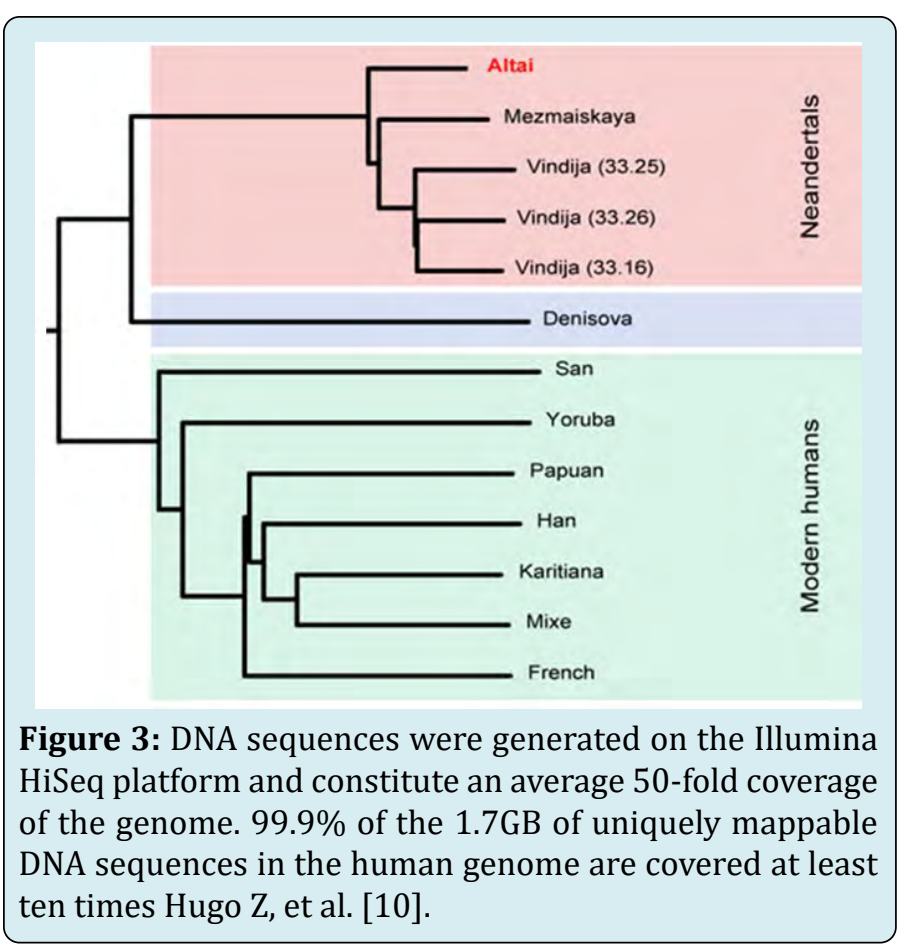

Contamination with modern human DNA, estimated from mitochondrial and nuclear DNA sequences, is around $1 \%$. The figure shows a tree relating this genome to the genomes of Neanderthals from Croatia, from Germany and from the Caucasus as well as the Denisovan genome recovered from a finger bone excavated at Deniosva Cave. It shows that this individual is closely related to these other Neanderthals. Thus, both Neanderthals and Denisovans have inhabited this cave in southern Siberia. Other groups looking in genetic databases for factors that influence COVID-19 severity have not flagged the DPP4 gene. But the work is provocative because it suggests some diabetes drugs, which target the cell surface protein, could help treat the disease. We want to put this finding out there quickly so people can systematically test if DPP4 could be a therapeutic target in patients with Coronavirus [40,41].

DPP4 may play a role in the infection of SARS-CoV-2. DPP4 should be a good binding partner for the protein called spike on the surface of the SARS-CoV-2 virus, based on comparing amino acid sequences and crystal structures of the enzyme and spike's established partner, ACE2. Another team, however, had earlier ruled out DPP4 as a SARS-CoV-2 receptor after finding the virus did not bind with it in cell line studies [42].

Hugo Z, et al. [10], also an evolutionary geneticist at Max Planck, have now highlighted DPP4 again. Most Europeans, Asians, and Native Americans harbor a handful of genes from Neanderthals, up $1.8 \%$ to $2.6 \%$ of their DNA.
Studies of ancient DNA in Neanderthal fossils have shown the hominin's DPP4 gene subtly differs from the typical human one. Hugo Z, et al. [10], examined whether that Neanderthal gene variant or others from the extinct species appear more often in people with severe cases of COVID-19 than in uninfected people. For that, they turned to the latest data released in October from the COVID-19 Host Genetics Initiative, which has collected genome information and COVID-19 status on many people from other studies or data banks [43-48]. They only searched for Neanderthal versions of genes in people who had severe COVID-19, which gave them a quick way to see whether these archaic genes influenced how living people responded to the coronavirus. The Neanderthal version of DPP4 popped up at a higher frequency in the genomes of 7885 people hospitalized with severe COVID-19 than in a control group. If a person had a single copy of the Neanderthal gene variant, they had double the risk of severe COVID-19 when infected, if both their copies of DPP4 were Neanderthal, their risk quadrupled [49].

The researchers estimate that between $1 \%$ and $4 \%$ of Europeans and Asians have inherited a Neanderthal version of the DPP4 gene [50-52]. A 2018 study by David Enard found that living humans have inherited a disproportionate number of Neanderthal variants of immune genes that target RNA viruses like coronaviruses, compared with genes that respond to DNA viruses $[53,54]$.

Science's COVID-19 reporting is supported by the Pulitzer Center and the Heising-Simons Foundation. It's one of the pandemic's puzzles: Most people infected by SARS-CoV-2 never feel sick, whereas others develop serious symptoms or even end up in an intensive care unit clinging to life. Age and preexisting conditions, such as obesity, account for much of the disparity. But geneticists have raced to see whether a person's DNA also explains why some get hit hard by the coronavirus, and they have uncovered tantalizing leads [55-57].

A U.K. group studying more than 2200 COVID-19 patients has pinned down common gene variants that are linked to the most severe cases of the disease, and that point to existing drugs that could be repurposed to help. Each one provides a potential target for treatment [58-72].

\section{Conclusion}

The hominin's DPP4 gene subtly differs from the typical human one. Hugo $\mathrm{Z}$, et al. [10], examined whether that Neanderthal gene variant or others from the extinct species appear more often in people with severe cases of COVID-19 than in uninfected people. For that, they turned to the latest data released in October 2020 from the COVID-19 Host Genetics Initiative, which has collected genome information 


\section{Open Access Journal of Mycology \& Mycological Sciences}

and COVID-19 status on many people from other studies or data banks. They only searched for Neanderthal versions of genes in people who had severe COVID-19, which gave them a quick way to see whether these archaic genes influenced how living people responded to the Coronavirus. If a person had a single copy of the Neanderthal gene variant, they had double the risk of severe COVID-19 when infected, if both their copies of DPP4 were Neanderthal, their risk quadrupled. The fact is Neanderthal Genes in modern humans, lowered the Immune System and faced them with many diseases such as HPV, Diabetes, Flu, COVID-19 and many infectious diseases. All humans contain this gene from 1 to 4 percent. East Asians, Europeans, Middle and South Americans conveys more, hence; native Africans contain less amounts of hominin's DPP4 gene. Therefore; East Asians, Europeans, Middle and South Americans are prone to severe COVID-19.

\section{References}

1. (2004) Cro-Magnons Conquered Europe, but Left Neanderthals Alone. PLOS Biology 2(12): e449.

2. Ovchinnikov IV, Götherström A, Romanova GP, Kharitonov VM, Lidén K, et al. (2000) Molecular analysis of Neanderthal DNA from the northern Caucasus. Nature 404(6777): 490-493.

3. Sánchez-Quinto F, Botigué LR, Civit S, Arenas C, AvilaArcos MC, et al. (2012) North African populations carry the signature of admixture with neandertals. PLOS ONE 7(10): e47765.

4. Fu Q, Li H, Moorjani P, Jay F, Slepchenko SM, et al. (2014) Genome sequence of a 45,000-year-old modern human from western Siberia. Nature 514(7523): 445-449.

5. Catherine B (2014) Humanity's forgotten return to Africa revealed in DNA. The New Scientist, pp: 410-440.

6. Endicott P, Ho SYW, Stringer C (2010) Using genetic evidence to evaluate four paleoanthropological hypotheses for the timing of Neanderthal and modern human origins (PDF). Journal of Human Evolution 59(1): 87-95.

7. Rieux A (2014) Improved calibration of the human mitochondrial clock using ancient genomes. Mol Biol Evol 31(10): 2780-2792.

8. Rogers AR, Bohlender RJ, Huff CD (2017) Early history of Neanderthals and Denisovans. Proc Natl Acad Sci USA 114(37): 9859-9863.

9. Carl Z (2020) DNA Linked to Covid-19 Was Inherited from Neanderthals, Study Finds-The stretch of six genes seems to increase the risk of severe illness from the coronavirus.

10. Hugo Z, Svante P (2020) The major genetic risk factor for severe COVID-19 is inherited from Neandertals. Nature 587(7835): 610-612.

11. Geir M (2006) Neanderthal genome project launches. NBC News.

12. Green RE, Malaspinas AS, Krause J, Briggs AW, Johnson PL, et al. (2008) A complete Neandertal mitochondrial genome sequence determined by high-throughput sequencing. Cell 134(3): 416-426.

13. Pennisi E (2009) Tales of a Prehistoric Human Genome. Science 323(5916): 866-871.

14. Green RE, Briggs AW, Krause J, Prüfer K, Burbano HA, et al. (2009) The Neandertal genome and ancient DNA authenticity. EMBO J 28(17): 2494-2502.

15. Prüfer K, Racimo F, Patterson N, Jay F, Sankararaman $\mathrm{S}$, et al. (2014) The complete genome sequence of a Neanderthal from the Altai Mountains. Nature 505(7481): 43-49.

16. Richard EG, Johannes K, Adrian WB, Tomislav M, Udo S, et al. (2010) A Draft Sequence of the Neandertal Genome. Science 328(5979): 710-722.

17. Pratas D, Hosseini M, Silva R, Pinho A, Ferreira P (2017) Visualization of Distinct DNA Regions of the Modern Human Relatively to a Neanderthal Genome. Iberian Conference on Pattern Recognition and Image Analysis. Springer. Lecture Notes in Computer Science 10255: 235-242.

18. (2009) Neanderthal genome sequencing yields surprising results and opens a new door to future studies (Press release). Lawrence Berkeley National Laboratory.

19. (2016) Surprise! 20 Percent of Neanderthal Genome Lives On in Modern Humans, Scientists Find. National Geographic.

20. Ding Q Hu Y, Xu S, Wang CC, Li H, et al. (2014) Neanderthal origin of the haplotypes carrying the functional variant Val92Met in the MC1R in modern humans. Molecular Biology and Evolution 31(8): 1994-2003.

21. Robert KL, Gabriel U, Eric BJ, Mark AW, Kristian JH, et al. (2013) Neanderthal and Denisova genetic affinities with contemporary humans: Introgression versus common ancestral polymorphisms. Gene 530(1): 83-94.

22. Henk B (2017) Neues Museum in Berlin 1175. 


\section{Open Access Journal of Mycology \& Mycological Sciences}

23. Benjamin V, Joshua MA (2015) Complex History of Admixture between Modern Humans and Neandertals. American Journal of Human Genetics 96(3): 454-461.

24. Kim BY, Lohmueller KE (2015) Selection and Reduced Population Size Cannot Explain Higher Amounts of Neanderthal Ancestry in East Asian than in European Human Populations. American Journal of Human Genetics 96(3): 448-53.

25. Ekaterina EK, Katarzyna B, Liu H, Zheng Y, Xi J, et al. (2014) Neanderthal ancestry drives the evolution of lipid catabolism in contemporary Europeans. Nature Communications 5: 3584.

26. Martin K, Ilan G, Melissa JH, Cesare F Prado-Martinez J, et al. (2016) Ancient gene flow from early modern humans into Eastern Neanderthals. Nature 530(7591): 429-433.

27. Sankararaman S Mallick S Dannemann M, Prüfer K, Kelso J, et al. (2014) The landscape of Neandertal ancestry in present-day humans. Nature 507(7492): 354-357.

28. Sriram S, Swapan M, Nick P, David R (2016) The Combined Landscape of Denisovan and Neanderthal Ancestry in Present-Day Humans. Current Biology 26(9): 1241-1247.

29. (2016) Neanderthals mated with modern humans much earlier than previously thought, study finds First genetic evidence of modern human DNA in a Neanderthal individual". Science Daily.

30. Fernando LM, Poznik GD, Castellano S, Bustamante CD (2016) The Divergence of Neandertal and Modern Human Y Chromosomes. The American Journal of Human Genetics 98(4): 728-734.

31. David E, Dmitri AP (2018) Evidence that RNA Viruses Drove Adaptive Introgression between Neanderthals and Modern Humans. Cell 175(2): 360-371.

32. (2020) Neanderthal genes may be a liability for Covid19 patients. Fairfax_AP.

33. Ian S (2020) Neanderthal genes increase risk of serious Covid-19, study claims.

34. Gokhman D, Lavi E, Prüfer K, Fraga MF, Riancho JA, et al. (2014) Reconstructing the DNA methylation maps of the Neandertal and the Denisovan. Science 344(6183): 523527.

35. Michel T, Francisco JA (2016) On Human Nature: Biology, Psychology, Ethics, Politics, and Religion.

36. Prüfer K, de Filippo C, Grote S, Mafessoni F, Korlević P, et al. (2017) A high-coverage Neandertal genome from Vindija Cave in Croatia. Science 358(6363): 655-658.

37. Fu Q (2014) Genome sequence of a 45,000-year-old modern human from western Siberia. Nature 514: 445449.

38. Browning SR, Browning BL, Zhou Y, Tucci S, Akey JM (2018) Analysis of human sequence data reveals two pulses of archaic Denisovan admixture. Cell 173(1): 5361.

39. Wall JD (2013) Higher levels of Neanderthal ancestry in East Asians than in Europeans. Genetics 194(1): 199209.

40. Kim BY, Lohmueller KE (2015) Selection, and reduced population size cannot explain higher amounts of Neandertal ancestry in East Asia than in European human populations. Am J Hum Genet 96: 454-461.

41. Vernot B, Akey JM (2015) Complex history of admixture between modern humans and Neandertals. Am J Hum Genet 96: 448-453.

42. Villanea FA, Schraiber JG (2019) Multiple episodes of interbreeding between Neanderthal and modern humans. Nat Ecol Evol 3: 39-44.

43. Dannemann M, Kelso J (2017) The contribution of Neanderthals to phenotypic variation in modern humans. Am J Hum Genet 101(4): 578-589.

44. Gittelman RM, Schraiber JG, Vernot B, Mikacenic C, Wurfel MM, et al. (2016) Archaic hominin admixture facilitated adaptation to out-of-Africa environments. Curr Biol 26(24): 3375-3382.

45. Gregory MD, Kippenhan JS, Eisenberg DP, Kohn PD, Dickinson D, et al. (2017) Neanderthal-derived genetic variation shapes modern human cranium and brain. Sci Rep 7: 6308.

46. McCoy RC, Wakefield J, Akey JM (2017) Impacts of Neanderthal-introgressed sequences on the landscape of human gene expression. Cell 168(5): 916-927.

47. Dannemann M, Prüfer K, Kelso J (2017) Functional implications of Neandertal introgression in modern humans. Genome Biol 18(1): 61.

48. Simoni CN, Vernot B, Bastarache L, Bottinger E, Carrell DS, et al. (2016) The phenotypic legacy of admixture between modern humans and Neandertals. Science 351(6274): 737-741.

49. Vernot B, Akey JM (2014) Resurrecting surviving 


\section{Open Access Journal of Mycology \& Mycological Sciences}

Neandertal lineages from modern human genomes. Science 343(6174): 1017-1021.

50. Sankararaman S, Mallick S, Dannemann M, Prüfer K, Kelso J, et al. (2014) The genomic landscape of Neanderthal ancestry in present-day humans. Nature 507: 354-357.

51. Steinrücken M, Spence JP, Kamm JA, Wieczorek E, Song YS (2018) Model-based detection and analysis of introgressed Neanderthal ancestry in modern humans. Mol Ecol 27(19): 3873-3888.

52. Meyer M, Kircher M, Gansauge MT, Li H, Racimo F, et al. (2012) A high-coverage genome sequence from an archaic Denisovan individual. Science 338(6104): 222226.

53. Prüfer K (2014) The complete genome sequence of a Neanderthal from the Altai Mountains. Nature 505: 4349.

54. Slon V (2018) The genome of the offspring of a Neanderthal mother and a Denisovan father. Nature 561: 113-116.

55. Skov L, etal. (2018) Detecting archaic introgression using an unadmixed outgroup. PLoS Genet 14: e1007641.

56. Kong A, Masson G, Frigge ML, Gylfason A, Zusmanovich P, et al. (2008) Detection of sharing by descent, long-range phasing and haplotype imputation. Nat Genet 40(9): 1068-1075.

57. Auton A, Brooks LD, Durbin RM, Garrison EP, Kang $\mathrm{HM}$, et al. (2015) A global reference for human genetic variation. Nature 526(7571): 68-74.

58. Sankararaman S, Mallick S, Patterson N, Reich D (2016) The combined landscape of Denisovan and Neanderthal ancestry in present-day humans. Curr Biol 26(9): 12411247.

59. Vernot B, Tucci S, Kelso J, Schraiber JG, Wolf AB, et al. (2016) Excavating Neandertal and Denisovan DNA from the genomes of Melanesian individuals. Science 352(6282): 235-239.

60. Schumer M, Xu C, Powell DL, Durvasula A, Skov L, et al. (2018) Natural selection interact with recombination to shape the evolution of hybrid genomes. Science 360(6389): 656-660.
61. Harris K, Pritchard JK (2017) Rapid evolution of the human mutation spectrum. eLife 6: e24284.

62. Moorjani P, Amorim CEG, Arndt PF, Przeworski M (2016) Variation in the molecular clock of primates. Proc Natl Acad Sci USA 113(38): 10607-10612.

63. Jónsson H, Sulem P, Kehr B, Kristmundsdottir S, Zink F, et al. (2017) Parental influence on human germline de novo mutations in 1,548 trios from Iceland. Nature 549: 519-522.

64. Harris K, Nielsen R (2016) The genetic cost of Neanderthal introgression. Genetics 203(2): 881-891.

65. Juric I, Aeschbacher S, Coop G (2016) The strength of selection against Neanderthal introgression. PLoS Genet 12(11).

66. Castellano S, Parra G, Sánchez-Quinto FA, Racimo F, Kuhlwilm M, et al. (2014) Patterns of coding variation in the complete exomes of three Neandertals. Proc Natl Acad Sci USA 111(18): 6666-6671.

67. McLaren W, Gil L, Hunt SE, Riat HS, Ritchie GRS, et al. (2016) The Ensembl Variant Effect Predictor. Genome Biol 17(1): 122.

68. Sveinbjornsson G, Albrechtsen A, Zink F, Gudjonsson SA, Oddson A, et al. (2016) Weighting sequence variants based on their annotation increases the power of wholegenome association studies. Nat Genet 48(3): 314-317.

69. Kote-Jarai Z, Olama AA, Leongamornlert D, Tymrakiewicz M, Saunders E, et al. (2011) Identification of a novel prostate cancer susceptibility variant in the KLK3 gene transcript. Hum Genet 129(6): 687-694.

70. Hajdinjak M, Fu Q Kelso J (2018) Reconstructing the genetic history of late Neanderthals. Nature 555: 652656.

71. Besenbacher S, Hvilsom C, Marques-Bonet T, Mailund T, Schierup MH (2019) Direct estimation of mutations in great apes reconciles phylogenetic dating. Nat Ecol Evol 3: 286-292.

72. Skov L, Macià CM, Sveinbjörnsson G, Mafessoni F, Lucotte EA, et al. (2020) The nature of Neanderthal introgression revealed by 27,566 Icelandic genomes. Nature 582: 7883. 